\title{
Commentary: Systemic adjuvant therapy for esophageal adenocarcinoma
}

\author{
Benny Weksler, MBA, MD
}

Esophageal cancer remains a challenging disease to treat, with poor prognosis. Most patients are diagnosed with either distant metastases or locoregional disease, and therapeutic interventions have limited effects. In patients without metastatic disease, neoadjuvant chemoradiation therapy is beneficial and improves survival as compared with surgery alone. However, despite advances, only $18 \%$ to $22 \%$ of patients with esophageal adenocarcinoma who receive neoadjuvant therapy have a pathologic complete response. Because clinical staging of esophageal cancer is unreliable, the true rate of downstaging as a result of neoadjuvant chemoradiation is unknown, but $\sim 80 \%$ of patients will have residual disease at the time of surgery with residual nodal disease in a significant portion. ${ }^{1}$ Positive nodal disease is a harbinger of systemic disease and poor survival, and the best management strategy for patients with residual nodal disease after neoadjuvant therapy is still debated. However, one promising development is the use of immunotherapy in the adjuvant setting.

In the current issue of JTCVS Open, Kandilis and colleagues ${ }^{2}$ report on survival after neoadjuvant therapy and esophagectomy in patients with adenocarcinoma of the distal esophagus. For this study, the patients were divided into 3 groups based on pathologic staging after neoadjuvant therapy and resection: patients with a complete response (ypT0N0, 22\%), patients with residual tumor

\footnotetext{
From the Division of Thoracic and Esophageal Surgery, Department of Thoracic and Cardiovascular Surgery, Allegheny General Hospital, Pittsburgh, Pa.

Disclosures: B.W. is a proctor for Intuitive Surgery and speaker for AstraZeneca.

The Journal policy requires editors and reviewers to disclose conflicts of interest and to decline handling or reviewing manuscripts for which they may have a conflict of interest. The editors and reviewers of this article have no conflicts of interest.

Received for publication Jan 3, 2021; revisions received Jan 3, 2021; accepted for publication Jan 4, 2021; available ahead of print Feb 13, 2021.

Address for reprints: Benny Weksler, MBA, MD, Division of Thoracic and Esophageal Surgery, Department of Thoracic and Cardiovascular Surgery, 320 E North Ave, 14th Fl, South Tower, Pittsburgh, PA 15212 (E-mail: benny.weksler@ahn. org).

JTCVS Open 2021;5:148-9

2666-2736

Copyright (C) 2021 The Authors. Published by Elsevier Inc. on behalf of The American Association for Thoracic Surgery. This is an open access article under the CC BY-NCND license (http://creativecommons.org/licenses/by-nc-nd/4.0/).

https://doi.org/10.1016/j.xjon.2021.01.002
}

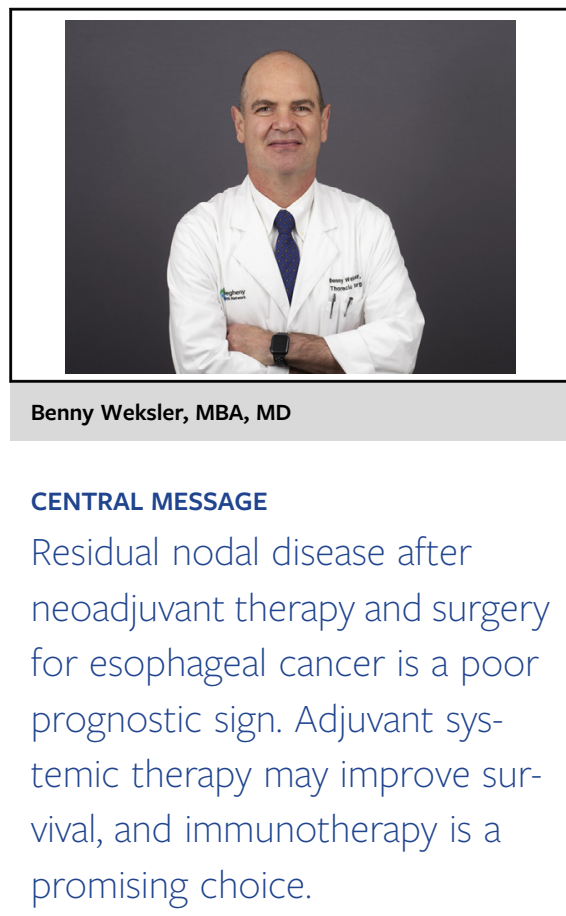

(ypT $+\mathrm{N} 0,46.2 \%)$, and patients at least 1 positive lymph node (ypTanyN1-3, 31.8\%). This study by Kandilis and colleagues confirmed a complete response rate of less than $25 \%$ in patients with esophageal adenocarcinoma undergoing preoperative therapy. It also confirmed that approximately one third of patients will have residual nodal disease after therapy. The main findings of the study were poor overall survival for patients with residual nodal disease, lack of a difference in survival between patients who had ypN1 versus ypN2-3 disease, and improved survival in patients who underwent adjuvant chemotherapy.

Previous retrospective studies, including several National Cancer Database studies and one retrospective multiinstitutional study, have similarly shown that adjuvant chemotherapy may improve survival in patients with residual disease. ${ }^{1,3,4}$ However, until recently, level 1 evidence showing improved survival in this group of patients was lacking. The similar overall survival observed between patients with ypN1 disease and patients with ypN2-3 disease is more difficult to explain and may be due to the effects of neoadjuvant therapy on tumor biology (tumors with biological behavior that trumps stage) or due to a relatively small sample size. The possibility that the study lacks power in this regard is suggested by the difference observed in disease-free survival between patients with ypTanyN1 and patients with ypTanyN2-3. 
A very exciting recent development is the finding that adjuvant nivolumab significantly prolonged disease-free survival in patients with residual disease after neoadjuvant therapy and resection of esophageal or gastroesophageal junction cancer. This was presented during the European Society of Medical Oncology meeting in September $2020^{5}$ and has already been adopted in treatment guidelines from the National Comprehensive Cancer Network. The potential for anti-programmed cell death protein 1/programmed cell death ligand 1 agents, which are immune checkpoint inhibitors, to improve the treatment of patients with esophageal cancer is a very welcome development and may be as practice-changing as the randomized studies on neoadjuvant therapies were in the early 2000s. ${ }^{6}$ In addition, a few studies investigating the use of immunotherapeutic agents in the neoadjuvant setting are currently accruing patients.

Surgery for esophageal cancer is changing, and more surgeries are being performed using minimally invasive techniques. Multiple studies have shown improvement in perioperative outcomes and quality of life using minimally invasive approaches. The study by Kandilis and colleagues reminds surgeons that our work is not limited to surgery. We should also be the drivers behind better neoadjuvant and adjuvant therapies to improve survival for patients with an otherwise-poor prognosis.

\section{References}

1. Samson P, Puri V, Lockhart AC, Robinson C, Broderick S, Patterson GA, et al. Adjuvant chemotherapy for patients with pathologic node-positive esophageal cancer after induction chemotherapy is associated with improved survival. $J$ Thorac Cardiovasc Surg. 2018;156:1725-35.

2. Kandilis A, Iniguez CB, Khalil H, Mazzola E, Jaklitsch MT, Swanson SJ, et al Residual lymph node disease and mortality following neoadjuvant chemoradiation and curative esophagectomy for distal esophageal adenocarcinoma. J Thorac Cardiovasc Surg Open. 2021;5:135-47.

3. Drake J, Tauer K, Portnoy D, Weksler B. Adjuvant chemotherapy is associated with improved survival in patients with nodal metastases after neoadjuvant therapy and esophagectomy. J Thorac Dis. 2019;11:2546-54.

4. Semenkovich TR, Subramanian M, Yan Y, Hofstetter WL, Correa AM, Cassivi SD, et al. Adjuvant therapy for node-positive esophageal cancer after induction and surgery: a multisite study. Ann Thorac Surg. 2019;108:828-36.

5. Kelly RJ, Ajani JA, Kuzdal J, Zander T, Van Cutsem E, Piessen G, et al. LBA9_PR adjuvant nivolumab in resected esophageal or gastroesophageal junction cancer (EC/GEJC) following neoadjuvant chemoradiation therapy (CRT): first results of the CheckMate 577 study. Ann Oncol. 2020;31:S1142-215.

6. Gebski V, Burmeister B, Smithers BM, Foo K, Zalcberg J, Simes J, et al. Survival benefits from neoadjuvant chemoradiotherapy or chemotherapy in oesophageal carcinoma: a meta-analysis. Lancet Oncol. 2007;8:226-34. 